\title{
BMJ A cohort study of mortality predictors Open and characteristics of patients with combined pulmonary fibrosis and emphysema
}

\author{
Tomoo Kishaba, ${ }^{1}$ Yousuke Shimaoka, ${ }^{2}$ Hajime Fukuyama, ${ }^{1}$ Kyoko Yoshida, ${ }^{3}$ \\ Maki Tanaka, ${ }^{4}$ Shin Yamashiro, ${ }^{1}$ Hitoshi Tamaki ${ }^{5}$
}

To cite: Kishaba T, Shimaoka $\mathrm{Y}$, Fukuyama $\mathrm{H}$, et al. A cohort study of mortality predictors and characteristics of patients with combined pulmonary fibrosis and emphysema. BMJ Open 2012;2:e000988. doi:10.1136/ bmjopen-2012-000988

- Prepublication history for this paper is available online. To view this file please visit the journal online (http://dx. doi.org/10.1136/ bmjopen-2012-000988).

Received 6 February 2012 Accepted 4 April 2012

This final article is available for use under the terms of the Creative Commons Attribution Non-Commercial 2.0 Licence; see http://bmjopen.bmj.com

\section{${ }^{1}$ Department of Respiratory} Medicine, Okinawa Chubu Hospital, Uruma, Japan 2Department of Respiratory Medicine, Okinawa Prefectural Miyako Hospital, Miyako, Japan

${ }^{3}$ Department of Home Care, Nakamura Clinic, Urasoe,

Japan

${ }^{4}$ Department of Respiratory Medicine, Kurashiki Central Hospital, Kurashiki, Japan ${ }^{5}$ Department of Respiratory Medicine, Sunagawa Medical Clinic, Uruma, Japan

Correspondence to Dr Tomoo Kishaba; kishabatomoo@gmail.com

\section{ABSTRACT}

Objectives: Our purpose was to assess the clinical data, predictors of mortality and acute exacerbation $(\mathrm{AE})$ in combined pulmonary fibrosis and emphysema (CPFE) patients.

Design: Single-centre retrospective cohort study.

Setting: Teaching hospital in Japan.

Participants: We identified 93 CPFE patients with highresolution computed tomographic (HRCT) through multidisciplinary discussion. Patients who had connective tissue disease, drug-associated interstitial lung disease and occupationally related interstitial lung disease, such as asbestosis and silicosis, were excluded.

Interventions: There were no interventions.

Methods: Medical records and HRCT scans from January 2002 through December 2007 were reviewed retrospectively at our hospital. Ninety-three patients had CPFE.

Results: The mean age of CPFE patients was 74 years. Idiopathic pulmonary fibrosis and non-specific interstitial pneumonia were observed as distinct HRCT patterns. Forty-two patients showed finger clubbing. Mean serum Krebs von den Lungen-6 (KL-6) and per cent predicted forced vital capacity (\%FVC) were $1089 \mathrm{IU} / \mathrm{l}, 63.86 \%$, respectively. Twenty-two patients developed $\mathrm{AE}$ during observation period. Baseline $\mathrm{KL}-6$ was a strong predictor of $A E(O R=1.0016, p=0.009)$. Finger clubbing $(H R=2.2620, p=0.015)$ and per cent predicted forced expiratory volume in one second $/ \%$ FVC more than $1.2(\mathrm{HR}=1.9259, \mathrm{p}=0.048)$ were independent predictors of mortality in CPFE.

Conclusions: Baseline serum KL-6 was a useful predictor of $A E$ (cut-off $=1050$, receiver operator characteristic curve: 0.7720 ), which occurred in $24 \%$ (22/93) of the CPFE patients. Finger clubbing and per cent predicted forced expiratory volume in one second/ $\% \mathrm{FVC}$ more than 1.2 were independent predictors of mortality.

Combined pulmonary fibrosis and emphysema (CPFE) has been recognised as a unique entity that is characterised by upper lobe emphysema and lower lobe fibrosis. ${ }^{1}$

\section{ARTICLE SUMMARY}

\section{Article focus}

- CPFE has recently been recognised as a new entity. Prognosis is often poor, and pulmonary hypertension is common. There is little information on clinical parameters and predictors of mortality.

- What is the most useful clinical predictor of mortality in CPFE?

- What is the most informative physiologic predictor of mortality in CPFE?

- What is the most sensitive clinical predictor of $\mathrm{AE}$ in CPFE?

- The study aim was to investigate non-invasive predictors of mortality in CPFE.

\section{Key messages}

- From a clinical point of view, finger clubbing is useful predictor of mortality in CPFE. In addition, ratio of $\% \mathrm{FEV}_{1}$ and $\% \mathrm{FVC}$ more than 1.2 were independent predictors of mortality in patients with CPFE too. Prediction of prognosis of these patients by minimally invasive methods may be quite useful.

Strengths and limitations of this study

- This study's strength was the definition of noninvasive, easily obtainable clinical and physiological measures of prognosis in CPFE. The major limitation of the study is the single-centre retrospective design.

Emphysema is sometimes recognized in the setting of idiopathic pulmonary fibrosis (IPF) and usually occurs with elevated lung volume, and patients with both emphysema and fibrosis (CPFE) usually have elevated lung volumes ${ }^{23}$ compared with patients with IPF alone. In CPFE, lung volume is preserved in many patients, even in those at advanced stages, because supervening fibrosis offsets the effect of emphysema. ${ }^{3-5}$ CPFE patients also more often have pulmonary arterial hypertension (PAH). ${ }^{6} \mathrm{PAH}$ has been shown to be a significant prognostic indicator for 
both $\mathrm{IPF}^{7} 8$ and chronic obstructive pulmonary disease. ${ }^{9}$ In patients with lung cancer, CPFE is more prevalent than fibrosis. ${ }^{10}$ Recently, CPFE syndrome has been individualised, partly on the basis of distinct characteristics observed by high-resolution computed tomography (HRCT) of the chest. ${ }^{11}$

There is very little information on predictors of mortality for CPFE. ${ }^{1}{ }^{12}$ Patients with CPFE often have severe dyspnoea and poor cardiopulmonary reserve, ${ }^{13} 14$ and many patients cannot tolerate invasive procedures such as video-assisted thoracoscopic surgery.

Thus, the objective of the present study was to determine the predictors of acute exacerbation (AE) and mortality in CPFE patients using non-invasive methods.

\section{METHODS}

\section{Study population and HRCT assessment}

We retrospectively investigated our medical records and HRCT scans from Okinawa Chubu Hospital, Okinawa, Japan, from 1 January 2002 through 31 December 2007. During this period, we had 319 interstitial lung disease (ILD) patients. Eligible patients were men and women aged 18 years or older with a proven diagnosis of IPF or non-specific interstitial pneumonia (NSIP) according to the American Thoracic Society/European Respiratory Society (ATS/ERS) statement. $^{15}$ Among all ILD patients, we identified 93 CPFE patients through multidisciplinary discussion including our pulmonologists and radiologists. We excluded patients if (1) they were without HRCT imaging, (2) had connective tissue disease, (3) had drug-associated ILD and (4) had occupationally related ILD, such as asbestosis and silicosis. Demographic and clinical data were obtained, including age, gender, smoking history, dyspnoea duration, comorbidity, crackles, clubbing, Krebs von den Lungen-6 (KL-6) levels and ultrasound cardiography findings. In terms of $\mathrm{PAH}$, we estimated with ultrasound cardiography. We also checked physiological data including forced expiratory volume in one second $\left(\mathrm{FEV}_{1}\right)$, per cent predicted forced vital capacity volume in one second $\left(\% \mathrm{FEV}_{1}\right)$, forced vital capacity $(\mathrm{FVC})$ and per cent predicted forced vital capacity (\%FVC). We only included pulmonary function data determined within 6 months of the date of HRCT.

The HRCT scan imaging patterns were evaluated according to the ATS/ERS criteria. ${ }^{15}$ We diagnosed IPF patients using the new ATS/ERS and Japanese Respiratory Society/Latin America Thoracic Association criteria. ${ }^{16}$ Patients who met the following criteria, as described by Cottin et al, ${ }^{1}$ were diagnosed as having CPFE: (1) the presence of emphysema on CT, defined as well-demarcated areas of decreased attenuation compared with contiguous normal lung, marginated by a very thin $(<1 \mathrm{~mm})$ wall or no wall and/or multiple bullae $(>1 \mathrm{~cm})$ with upper zone predominance, and (2) the presence of significant pulmonary fibrosis on CT, defined as reticular opacities with peripheral and basal predominance, with or without traction bronchiectasis that occurs with or without honeycombing. Regarding $\mathrm{AE}$, we defined by the following criteria ${ }^{17}$ : (1) sudden deterioration of dyspnoea within 30 days, (2) new bilateral infiltration on chest radiograph and (3) pulmonary infection or other known causes were excluded by bronchoalveolar lavage. Survival time was defined from the date of HRCT to death or last observation date. The Ethics Committee of Okinawa Chubu Hospital approved this study protocol.

\section{Statistical methods}

Clinical data are presented as means \pm SDs or medians (range), depending on distribution. Group comparisons were made using unpaired $\mathrm{t}$ tests, the Wilcoxon rank sum test, $\chi^{2}$ statistics and Fisher's exact test, as appropriate. Logistic regression analysis was performed to determine the relationship between clinical parameters and AE. A Cox proportional hazards model analysis was performed to determine the relationships between clinical parameters, physiological indices, HRCT imaging patterns and survival. Clinical data analyses were performed using STATA software V.11.0 (Stata Corp). Statistical significance was defined as a $\mathrm{p}$ value $<0.05$.

\section{RESULTS}

\section{Patient characteristics, AE and clinical parameters}

The flow diagram in figure 1 shows how the patients were identified. Ninety-three CPFE patients (76 men, 17 women) were identified between 2002 and 2007. The mean age was 73 years, and $82 \%$ of the patients were men. The mean time from symptoms to diagnosis was 12.68 months $(0-96$ months $)$. The mean follow-up period was 30.7 months (0-74.6 months). All patients had histories of smoking (mean: 62 pack-years). The mean modified Medical Research Council (mMRC) breathlessness score was 2.5. Bibasilar fine crackles were auscultated in all patients and $42(45 \%)$ had finger clubbing. The baseline $\% \mathrm{FEV}_{1}\left(\mathrm{FEV}_{1} /\right.$ average $\% \mathrm{FEV}_{1}$ for similar age, sex and body composition) was $70.95 \%$, and the baseline per cent predicted FVC was $63.86 \%$. During observation period, 67 patients $(72 \%)$ died. The clinical characteristics of both survivors and non-survivors are summarised in table 1 .

The mean partial pressures of oxygen $\left(\mathrm{PaO}_{2}\right)$ and carbon dioxide $\left(\mathrm{PaCO}_{2}\right)$ were 63 and $43 \mathrm{~mm} \mathrm{Hg}$, respectively. Thirty-two patients $(34 \%)$ received home oxygen therapy and $36(39 \%)$ had PAH. The mean systolic pulmonary arterial pressure was $62 \mathrm{~mm} \mathrm{Hg}$. CPFE patients frequently have been reported to have lung cancer, especially squamous cell carcinoma. ${ }^{10}{ }^{18}$ However, in our cohort, only 12 (13\%) patients developed lung cancer.

Among the 93 patients, 22 (24\%) developed AE, which met the ATS/ERS criteria. ${ }^{15}$ We performed univariate analysis to determine predictors of AE. Age, mMRC score, CT pattern and baseline serum KL-6 were identified as possible predictors of AE. Logistic regression analysis was performed for these four factors, baseline 
319 Interstitial lung disease patients were identified from 2002 to 2007

226 Patients were excluded

$\rightarrow$ Due to ineligibility

$\downarrow$

93 Patients followed up

\section{UIP/CPFE \\ $(n=68)$}

Figure 1 Flow diagram in CPFE patients.

serum KL-6 was found to be the strongest predictor of AE in the CPFE patients $(\mathrm{OR}=1.0016, \mathrm{p}=0.009)$ (table 2). Using receiver operator characteristic curve (ROC) analysis, the useful KL-6 threshold was determined to be 1050 (ROC: 0.7720).

\section{HRCT imaging and predictors of mortality}

According to the ATS/ERS criteria, ${ }^{15}{ }^{16}$ the patients were divided into those with usual interstitial pneumonia (UIP) patterns and those with NSIP patterns. There were 68 patients in the IPF-pattern group and 25 patients in the NSIP-pattern group. The HRCT images also showed patterns indicating that 51 patients had paraseptal emphysema, 28 had centrilobular emphysema and 14 had panlobular emphysema. Detailed results are presented in (table 3).

The mean survival of CPFE patients was 30.7 months (0.10-75.63 months) (figure 2). Patients with finger clubbing or increased ratio of $\% \mathrm{FEV}_{1}$ to $\% \mathrm{FVC}$ showed poor survival in CPFE patients (figures 3 and 4). Regarding ratio of $\% \mathrm{FEV}_{1}$ to $\% \mathrm{FVC}$, we chose 1.2 which was most useful threshold for predictor of mortality using ROC analysis (ROC: 0.7671). Initially, we performed univariate analysis with a cut-off value of 0.1 , which showed that baseline KL-6, finger clubbing, $\mathrm{PaO}_{2}$ and $\% \mathrm{FEV}_{1} / \% \mathrm{FVC}>1.2$ were independent predictors of mortality. Cox proportional hazards regression analysis showed that finger clubbing $(\mathrm{HR}=2.2620, \mathrm{p}=0.015)$ and ratio of $\% \mathrm{FEV}_{1}$ to $\% \mathrm{FVC}$ more than 1.2 $(\mathrm{HR}=1.9259, \mathrm{p}=0.048)$ were the strongest independent predictors of mortality in CPFE patients at our hospital (table 4).

\section{DISCUSSION}

Previous studies have reported a high prevalence of PAH and lung cancer in CPFE patients. ${ }^{10}$ These comorbidities were associated with poor prognosis; the 1-year survival rate for CPFE patients with PAH was only $60 \% .^{6}{ }^{11}$ Among these patients, high mean pulmonary arterial pressure, high pulmonary vascular resistance, high heart rate and low diffusing capacity for carbon monoxide (DLco) were significantly associated with poor outcome. In one study, CPFE patients had a fivefold higher mortality risk (adjusted HR 5.10, 95\% CI 1.75 to 14.9) in non-malignant situations. ${ }^{19}$ In the present study, only 12

Table 1 Patient clinical characteristics in CPFE

\begin{tabular}{|c|c|c|c|}
\hline & Survivors $(n=26)$ & Non-survivors $(n=67)$ & p Value \\
\hline Age, year (mean) & $73.19 \pm 1.18(57-84)$ & $73.83 \pm 7.07$ (56-91) & 0.5815 \\
\hline Male sex, \% & 85 & 81 & 0.6570 \\
\hline Pack-year & $60 \pm 22.0(5-110)$ & $64 \pm 31.4(0-180)$ & 0.5754 \\
\hline mMRC scale & $2.6 \pm 0.88(1-4)$ & $2.5 \pm 0.93(1-4)$ & 0.5091 \\
\hline Dyspnoea duration, months & $11.04 \pm 5.73(0-18)$ & $13.07 \pm 14.20(0-96)$ & 0.4821 \\
\hline Clubbing, \% & 12 & 55 & $<0.0001$ \\
\hline KL-6, IU/I & $852 \pm 278(505-1200)$ & $1174 \pm 725(201-4250)$ & 0.0413 \\
\hline Systolic PAP, mm Hg & 45 & 75 & $<0.0001$ \\
\hline Baseline $\mathrm{FEV}_{1}, \%$ & $71.14 \pm 8.72(59.6-103.9)$ & $70.88 \pm 9.25(31.4-106.3)$ & 0.9128 \\
\hline Baseline FVC, \% & $68.52 \pm 9.09(57-99.7)$ & $61.89 \pm 9.48(24.9-82.3)$ & 0.0058 \\
\hline НOT, \% & 12 & 43 & 0.0035 \\
\hline Paraseptal emphysema, \% & 19 & 69 & $<0.0001$ \\
\hline Acute exacerbation, n (\%) & $0(0)$ & $22(32)$ & 0.0007 \\
\hline$\% F E V_{1} / \% F V C>1.2, \%$ & 19 & 79 & $<0.0001$ \\
\hline Cancer, \% & 0 & 18 & 0.1068 \\
\hline Cardiovascular, \% & 27 & 40 & 0.2339 \\
\hline Ejection fraction, \% & $58.2 \pm 3.90$ & $56.9 \pm 5.19$ & 0.2337 \\
\hline Survival time, months & $50.16 \pm 17.79(26-96)$ & $25.68 \pm 21.54(1-98)$ & $<0.0001$ \\
\hline
\end{tabular}


Table 2 Predictor of acute exacerbation in CPFE patients

\begin{tabular}{lll}
\hline & OR (95\% Cl) & p Value \\
\hline Age & $0.9691(0.8985$ to 1.0453$)$ & 0.417 \\
mMRC scale & $0.6681(0.3538$ to 1.2616$)$ & 0.214 \\
Dyspnoea duration & $0.8967(0.8169$ to 0.9844$)$ & 0.022 \\
Baseline KL-6 & $1.0016(1.0003$ to 1.0027$)$ & 0.009 \\
CT pattern & $0.7612(0.2247$ to 2.5779$)$ & 0.661 \\
\hline CPFE, combined pulmonary fibrosis and emphysema; mMRC, \\
modified Medical Research Council.
\end{tabular}

of 93 patients had lung cancer in contrast to the number reported in a previous study. ${ }^{10}$ Our institution is a teaching and community hospital, and the patient population may be different from that of a university hospital.

The pulmonary function indices of the CPFE patients included in the present study were rather different from those in previous reports. ${ }^{120}$ The CPFE patients in those studies had greater preserved lung volume despite reduced DLco, reduced transfer coefficient for carbon monoxide (Kco) and hypoxaemia. Jankowich and Rounds $^{21}$ reported that CPFE altered physiology but had a mortality rate similar to that of IPF. In addition, Peng et $a l^{22}$ reported similar physiology results for CPFE. In our study, the mean per cent predicted FVC was $63.86 \%$ and that of $\mathrm{FEV}_{1}$ was $70.95 \%$, which showed more restrictive impairment compared with previous cases. This finding can be explained by the greater volume loss of the lower lung field due to severe fibrosis rather than by the offset effect of emphysema. ${ }^{23}$ This finding might also be because our cohort had less emphysema area compared with the previously reported cases. Another possibility is that the patients might have been in a different phase of CPFE. Recently, Rogliani et $a l^{24}$ reported the pathology of IPF and emphysema. They evaluated 17 biopsy-proven UIP patients and found

\begin{tabular}{|c|c|c|c|}
\hline & $\begin{array}{l}\text { UIP pattern } \\
(n=68)\end{array}$ & $\begin{array}{l}\text { NSIP pattern } \\
(n=25)\end{array}$ & $\begin{array}{l}\text { All } \\
(n=93)\end{array}$ \\
\hline \multicolumn{4}{|l|}{ Emphysema pattern } \\
\hline Paraseptal, \% & 57 & 48 & 55 \\
\hline Centrilobular, \% & 29 & 32 & 30 \\
\hline Panlobular, \% & 14 & 20 & 15 \\
\hline \multicolumn{4}{|l|}{ Fibrosis pattern } \\
\hline $\begin{array}{l}\text { Traction } \\
\text { bronchiectasis, \% }\end{array}$ & 96 & 88 & 94 \\
\hline Reticulation, \% & 91 & 88 & 90 \\
\hline Honeycombing, \% & 100 & 0 & 73 \\
\hline $\begin{array}{l}\text { Ground-glass } \\
\text { opacity, \% }\end{array}$ & 34 & 100 & 52 \\
\hline Consolidation, \% & 29 & 60 & 38 \\
\hline \multicolumn{4}{|c|}{$\begin{array}{l}\text { CPFE, combined pulmonary fibrosis and emphysema; HRCT, high- } \\
\text { resolution computed tomography; IPF, idiopathic pulmonary } \\
\text { fibrosis; NSIP, non-specific interstitial pneumonia; UIP, usual } \\
\text { interstitial pneumonia. }\end{array}$} \\
\hline
\end{tabular}

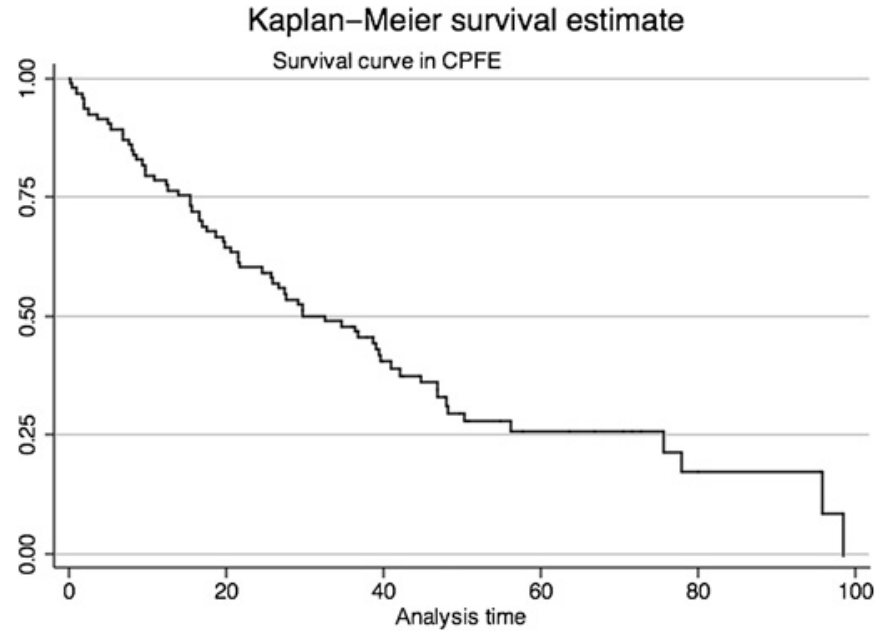

Figure 2 Survival curve in CPFE patients.

fibroblasts in areas of parenchymal destruction from emphysema/UIP-expressed matrix metalloproteinase (MMP)-2, MMP-9, MMP-7 and membrane type 1 (MT1)-MMP at significantly higher levels when compared with emphysema subjects. On the basis of this result, similar to the findings of the study by Rogliani et al cited above, interstitial fibroblast activation could be stimulated to a greater degree in the areas of lung destruction in CPFE compared with emphysema alone, as in exaggerated tissue remodelling. Therefore, some of the CPFE patients may have had more intense fibrosis, which contributed to reduced FVC.

In the analysis of the HRCT images, the patients were divided into two groups by UIP pattern and NSIP pattern according to the ATS/ERS criteria. ${ }^{15}{ }^{16}$ All the UIPpattern patients had honeycombing, and the NSIPpattern patients more often had consolidation $(60 \%$ vs $29 \%$ ) and ground-glass opacity (100\% vs $34 \%)$. These findings were very similar to those from a recent report on HRCT for NSIP. ${ }^{25}$ In addition, Sumikawa et $a l^{26}$ reported that traction bronchiectasis and fibrosis scores

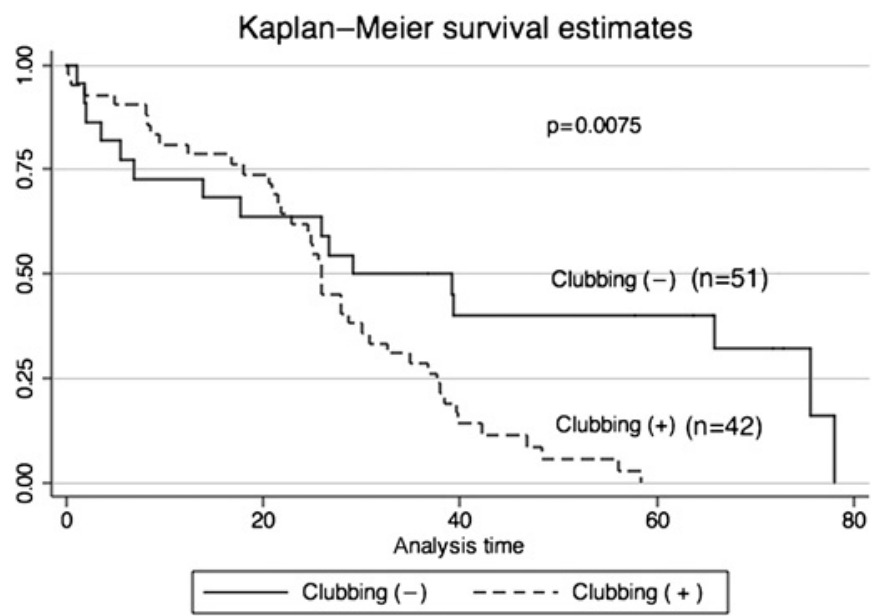

Figure 3 CPFE patients with clubbing show poor survival compared with that of without clubbing. 


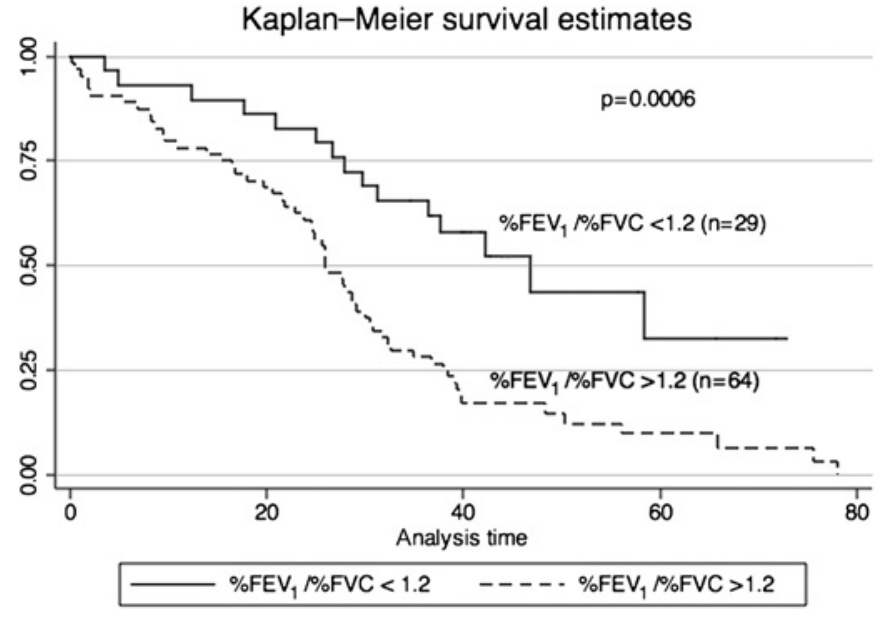

Figure 4 Ratio of \%FEV 1 and per cent predicted forced vital capacity more than 1.2 show poor survival rather than that of $<1.2$ in CPFE patients.

were associated with poor prognosis in pathological UIP patients. In the present study, HRCT pattern was not an independent prognostic predictor. CPFE patients usually have more severe $\mathrm{PAH}$, low cardiac index ${ }^{6}$ and are disabled, ${ }^{27}$ which we observed in our cohort. Thus, most CPFE patients cannot tolerate invasive procedures such as video-assisted thoracic surgery. Therefore, we cannot compare biopsy-proven UIP with CPFE equally.

$\mathrm{AE}$ is a relentlessly progressive status and is associated with poor outcome. ${ }^{28}$ Thus, we evaluated AE of CPFE. During the observation period (mean: 30.7 months), 22 patients $(24 \%)$ developed AE. The annual incidence of $\mathrm{AE}$ is $9.4 \%$. This finding is similar to that reported in IPF recently. ${ }^{29}$ Kondoh et $a l^{30}$ reported that high mMRC score, high body mass index and decline in FVC at 6 months were significant independent risk factors for AE-IPF. KL-6 levels in ILD patients reflect the overall extent of interstitial lesions. Among the many clinical parameters, baseline serum KL-6 was the most powerful predictor of $\mathrm{AE}$ in our $\mathrm{CPFE}$ patients. ROC analysis showed that the useful threshold was 1050 (ROC $=0.7720)$.

Finally, we investigated the prognostic predictors of CPFE in our cohort. FVC has been reported robust powerful predictor of mortality in IPF patients. ${ }^{31}$ DLco often show variable value, so reproducibility is rather poor. In addition when FVC is reduced, DLco cannot be obtained with single-breath method. Therefore, we chose $\% \mathrm{FEV}_{1}, \% \mathrm{FVC}$ and ratio of these value as important

Table 4 Results of the Cox proportional hazards regression analysis of mortality in CPFE patients

\begin{tabular}{lll}
\hline & HR (95\% Cl) & p Value \\
\hline Finger clubbing & $2.2620(1.1746$ to 4.3560$)$ & 0.015 \\
$\%$ FEV $1 /$ & $1.9259(1.0057$ to 3.6883$)$ & 0.048 \\
$\%$ FVC (>1.2) & & \\
\hline
\end{tabular}

CPFE, combined pulmonary fibrosis and emphysema; \%FEV ${ }_{1}$, per cent predicted forced expired volume in one second; FVC, forced vital capacity; \%FVC, per cent predicted forced vital capacity. indices out of pulmonary function parameters. Univariate analysis revealed that KL-6, finger clubbing, $\mathrm{PaO}_{2}$ and ratio of $\% \mathrm{FEV}_{1}$ to $\% \mathrm{FVC}$ were independent predictors. Regression analysis using a Cox proportional hazards model showed that finger clubbing and ratio of $\% \mathrm{FEV}_{1}$ to $\%$ FVC more than 1.2 were the strongest independent predictors of mortality in CPFE at our hospital. In CPFE patients, lung volume is usually preserved. Therefore, absolute value of FVC or \% FVC itself has been reported to be not robust predictor of critical event. However, ratio of $\% \mathrm{FEV}_{1}$ to $\% \mathrm{FVC}$ may be useful parameter in subgroup of CPFE patients. In terms of different cut-off value of this ratio, $\mathrm{CPFE}$ patients tend to have more mild restrictive impairment compared with that of IPF patients. Another interesting finding was that finger clubbing is related to poor survival in CPFE patients. Finger clubbing usually shows chronicity in ILD patients. However, it predicted clinical course in CPFE patients at our cohort. So, we insist on the importance of initial careful evalution of physical findings in CPFE.

This time, we did not evaluate the treatment in CPFE patients. Currently, there is no consensus on treatment of CPFE with PAH. ${ }^{32} 33$ This is a vital topic for future study.

There were several limitations in our study. First, this was a single-centre, uncontrolled design retrospective study, which means that it is possible that important data were not collected. Second, we did not measure the exact areas of emphysema and fibrosis. Therefore, our cohort may have been at a different stage compared with previous CPFE patients. Third, most of our patients could not undergo surgical biopsy because of disability and reduced lung function. Thus, we could not evaluate the detailed pathology of our CPFE patients. Fourth, we did not evaluate serial pulmonary function. Recently, du Bois $e t a l^{34}$ reported that per cent predicted FVC and the 24 week change in FVC were useful predictors of mortality in IPF. Therefore, it might be helpful to measure serial FVC as a prognostic predictor in CPFE. Lastly, in keeping with previous reports, our study patients were all heavy smokers. Therefore, we could not distinguish CPFE from smoking-related NSIP. ${ }^{35}$ However, even considering these limitations, prediction of prognosis using minimally invasive methods in these patients may be quite useful.

In conclusion, CPFE patients showed poor survival in our cohort. CPFE patients often develop AE, for which baseline serum KL-6 was a useful predictor. Finger clubbing and $\% \mathrm{FEV}_{1} / \% \mathrm{FVC}$ more than 1.2 were independent prognostic predictors of mortality in patients with CPFE. A multicenter study of this new entity is warranted for further research.

Acknowledgements We would like to thank all residents for their time and efforts with the collection of medical records at Okinawa Chubu Hospital. In addition, we thank Dr Yasutani for interpretation of radiological findings.

Contributors TK, YS, HF, KY, MT, SY and HT have substantial contribution to study conception and design, acquisition of data or analysis and interpretation of data. TK, YS, HF, KY, MT, SY and HT have substantial contribution to 
drafting the article or revising it critically for important intellectual content. TK, YS, HF, KY, MT, SY and HT have substantial contribution to final approval of the version to be published.

Funding This research received no specific grant from any funding agency in the public, commercial or not-for-profit sectors.

Competing interests None.

Ethics approval Ethics approval was provided by the Ethics Committee of Okinawa Chubu Hospital.

Provenance and peer review Not commissioned; externally peer reviewed.

Data sharing statement There are no additional data available.

\section{REFERENCES}

1. Cottin V, Nuns H, Billet PY, et al; Group d'Etude et de Recherche sur les Maladies Orphelines Pulmonaries (GERM O P). Combined pulmonary fibrosis and emphysema: a distinct underrecognised entity. Eur Respir J 2005;26:586-93.

2. Wiggins J, Strickland B, Turner-Warwick M. Combined cryptogenic fibrosing alveolitis and emphysema: the value of high resolution computed tomography in assessment. Respir Med 1990;84:365-9.

3. Mura M, Zompatori M, Pacilli AM, et al. The presence of emphysema further impairs physiologic function in patients with idiopathic pulmonary fibrosis. Respir Care 2006:51:257-65.

4. Strickland $\mathrm{NH}$, Hughes JM, Hart DA, et al. Cause of regional ventilation-perfusion mismatching in patients with idiopathic pulmonary fibrosis: a combined CT and scintigraphic study. AJR Am J Roentgenol 1993;161:719-25.

5. Doherty MJ, Pearson MG, O'Grady EA, et al. Cryptogenic fibrosing alveolitis with preserved lung volumes. Thorax 1997;52:998-1002.

6. Cottin V, Le Pavec J, Prevot G, et al; GERM“O”P. Pulmonary hypertension in patients with combined pulmonary fibrosis and emphysema syndrome. Eur Respir J 2010;35:105-11.

7. Lettieri CJ, Nathan SD, Barnett SD, et al. Prevalence and outcomes of pulmonary arterial hypertension in advanced idiopathic pulmonary fibrosis. Chest 2006;129:746-52.

8. Hamada K, Nagai S, Tanaka S, et al. Significance of pulmonary arterial pressure and diffusion capacity of the lung as prognosticator in patients with idiopathic pulmonary fibrosis. Chest 2007;131:650-6.

9. Oswald-Mammosser M, Weitzenblum E, Quoix E, et al. Prognostic factors in COPD patients receiving long-term oxygen therapy. Importance of pulmonary artery pressure. Chest 1995;107:1193-8.

10. Usui K, Tanai $\mathrm{C}$, Tanaka $\mathrm{Y}$, et al. The prevalence of pulmonary fibrosis combined with emphysema in patients with lung cancer. Respirology 2011;16:326-31.

11. Cottin V, Cordier JF. The syndrome of combined pulmonary fibrosis and emphysema. Chest 2009;136:1-2

12. Mejia M, Carrillo G, Rojas-Serrano J, et al. Idiopathic pulmonary fibrosis and emphysema: decreased survival associated with severe pulmonary arterial hypertension. Chest 2009;136:10-15.

13. Thabut G, Dauriat G, Stern JB, et al. Pulmonary hemodynamics in advanced COPD candidates for lung volume reduction surgery or lung transplantation. Chest 2005;127:1531-6.

14. Chaouat A, Naeije R, Weitzenblum E. Pulmonary hypertension in COPD. Eur Respir J 2008;32:1371-85.

15. American Thoracic Society. American thoracic Society/European Respiratory Society International multidisciplinary consensus Classification of the idiopathic interstitial Pneumonias. Am J Respir Crit Care Med 2002;165:277-304

16. Raghu G, Collard H, Egan J, et al; ATS/ERS/JRS/ALAT Committee on idiopathic pulmonary fibrosis. An official ATS/ERS/JRS/ALAT statement: idiopathic pulmonary fibrosis: evidence-based guidelines for diagnosis and management. Am J Respir Crit Care Med 2011;183:788-824.

17. Collard HR, Moore BB, Flaherty KR, et al; Idiopathic pulmonary fibrosis clinical research Network Investigators. Acute exacerbations of idiopathic pulmonary fibrosis. Am J Respir Crit Care Med 2007; 176:636-43.

18. Kitaguchi $\mathrm{Y}$, Fujimoto $\mathrm{K}$, Hanaoka M, et al. Clinical characteristics of combined pulmonary fibrosis and emphysema. Respirology 2010;156:265-71.

19. Lee $\mathrm{CH}$, Kim HJ, Park CM, et al. The impact of combined pulmonary fibrosis and emphysema on mortality. Int J Tuberc Lung Dis 2011;15:1111-16.

20. Akagi T, Matsumoto T, Harada T, et al. Coexistent emphysema delays the decrease of vital capacity in idiopathic pulmonary fibrosis. Respir Med 2009;103:1209-15.

21. Jankowich MD, Rounds S. Combined pulmonary fibrosis and emphysema alters physiology but has similar mortality to pulmonary fibrosis without emphysema. Lung 2010;188:365-73.

22. Peng $\mathrm{M}$, Cai $\mathrm{F}$, Tian $\mathrm{XL}$, et al. [Combined pulmonary fibrosis and emphysema syndrome]. Zhonghua Jie He He Hu Xi Za Zhi 2010;33:515-18.

23. Wells A, Desai S, Rubens M, et al. Idiopathic pulmonary fibrosis: a composite physiologic index derived from disease extent observed by computed tomography. Am J Respir Crit Care Med 2003;167:962-9.

24. Rogliani P, Mura M, Mattia P, et al. HRCT and histopathological evaluation of fibrosis and tissue destruction in IPF associated with pulmonary emphysema. Respir Med 2008;102:1753-61.

25. Hozumi $H$, Nakamura $Y$, Johkoh $T$, et al. Nonspecific interstitial pneumonia: prognostic significance of high-resolution computed tomography in 59 patients. J Comput Assist Tomogr 2011;35:583-9.

26. Sumikawa $\mathrm{H}$, Johkoh $\mathrm{T}$, Colby $\mathrm{T}$, et al. Computed tomography findings in pathological usual interstitial pneumonia: relationship to survival. Am J Respir Crit Care Med 2008;177:433-9.

27. Nathan SD, Shlobin OA, Barnett SD, et al. Right ventricular systolic pressure by echocardiography as a predictor of pulmonary hypertension in idiopathic pulmonary fibrosis. Respir Med 2008;102:1305-10.

28. Ley $\mathrm{B}$, Collard $\mathrm{H}$, King $\mathrm{T}$. Clinical course and prediction of survival in idiopathic pulmonary fibrosis. Am J Respir Crit Care Med 2011;183:431-40.

29. Song JW, Hong SB, Lim CM, et al. Acute exacerbation of idiopathic pulmonary fibrosis: incidence, risk factors and outcome. Eur Respir $J$ 2011;37:356-63.

30. Kondoh $\mathrm{Y}$, Taniguchi $\mathrm{H}$, Katsuta $\mathrm{T}$, et al. Risk factors of acute exacerbation of idiopathic pulmonary fibrosis. Sarcoidosis Vasc Diffuse Lung Dis 2010;27:103-10.

31. du Bois RM, Weycker D, Albera C, et al. Forced vital capacity in patients with idiopathic pulmonary fibrosis: test properties and minimal clinically important difference. Am J Respir Crit Care Med 2011;184:1382-9.

32. Cushley MJ, Davison AG, du Bois RM, et al. The diagnosis, assessment and treatment of diffuse parenchymal lung disease in adults. Thorax 1999;54:S1-30.

33. Portillo Carroz K, Roldan Sanchez J, Morera Prat J. [Combined pulmonary fibrosis and emphysema]. Arch Bronchoneumol 2010;46:646-51.

34. du Bois R, Weycker D, Albera C, et al. Ascertainment of individual risk of mortality for patients with idiopathic pulmonary fibrosis. Am $J$ Respir Crit Care Med 2011;184:459-66.

35. Marten K, Milne D, Antoniou K, et al. Non-specific interstitial pneumonia in cigarette smokers: a CT study. Eur Radiol 2009;19:1679-85. 